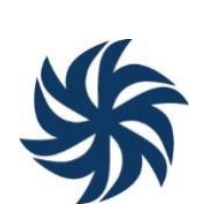

\title{
O LEGISLATIVO E AS OPORTUNIDADES DE PARTICIPAÇÃO ONLINE SOBRE A PANDEMIA DO COVID-19: O ABISMO ENTRE AS INICIATIVAS DOS PARLAMENTOS EM NÍVEL FEDERAL E ESTADUAL
}

\author{
LEGISLATIVE AND ONLINE PARTICIPATION OPPORTUNITIES ON \\ COVID-19 PANDEMIC: THE GAP BETWEEN PARLIAMENTARY \\ INITIATIVES AT FEDERAL AND STATE LEVELS
}

\author{
OPORTUNIDADES DE PARTICIPACIÓN LEGISLATIVA Y EN LÍNEA \\ SOBRE LA PANDEMIA DE COVID-19: EL ABISMO ENTRE LAS \\ INICIATIVAS PARLAMENTARIAS A NIVEL FEDERAL Y ESTATAL
}

\author{
Tatiana Güenaga Aneas ${ }^{1}$ \\ Samuel Barros ${ }^{2}$ \\ Juliana Marinho ${ }^{3}$
}

\begin{abstract}
Resumo: O presente artigo tem como objetivo mapear e discutir as iniciativas digitais de participação promovidas pelas casas legislativas brasileiras em nível federal e estadual em resposta à pandemia provocada pelo novo Covid-19 (Sars-CoV-2). Os resultados indicam uma diferença abissal entre as iniciativas federais (65) e estaduais e do Distrito Federal (8). Enquanto as experiências mais robustas foram promovidas pela Câmara dos Deputados (37) e pelo Senado Federal (28), em nível subnacional apenas a Câmara Legislativa do Distrito Federal (7) e a Assembleia Legislativa do Estado de Pernambuco (1) registraram casos. Nos websites das Assembleias Legislativas dos demais 25 estados não foram registradas iniciativas que viabilizasse a participação da sociedade nas questões relacionadas à pandemia do Covid-19.
\end{abstract}

Palavra-chave: Parlamento Digital; Democracia Digital; Participação Online; Pandemia do Covid-19

Abstract: This article aims to map and discuss the digital participation initiatives promoted by Brazilian legislatures at the federal and state levels in response to the pandemic caused by the new Covid-19 (SarsCoV-2). The results indicate an abysmal difference between federal (65) and state and Federal District (8) initiatives. While the most robust experiences were promoted by the Chamber of Deputies (37) and the Federal Senate (28), at the subnational level only the Legislative Chamber of the Federal District (7) and the Legislative Assembly of the State of Pernambuco (1) registered cases. On the websites of the Legislative Assemblies of the other 25 states, no initiatives were registered to enable society to participate in issues related to the Covid-19 pandemic.

Keywords: Digital Parliament; Digital Democracy; Online Participation; Covid-19 Pandemic.

\footnotetext{
${ }^{1}$ Professora do Programa de Pós-graduação em Comunicação da Universidade Federal de Sergipe. Doutora em Comunicação e Cultura Contemporâneas pela Universidade Federal da Bahia.

${ }^{2}$ Professor da Universidade Federal do Recôncavo da Bahia (UFRB), docente permanente do Programa de PósGraduação em Comunicação e Cultura Contemporâneas (PósCom-UFBA), pesquisador do Instituto Nacional de Ciência e Tecnologia em Democracia Digital (INCT.DD).

${ }^{3}$ Bacharela em Humanidades pela Universidade Federal da Bahia (UFBA), estudante de Comunicação Social com habilitação em Jornalismo na mesma instituição e bolsista de Iniciação Científica no Instituto Nacional de Ciência e Tecnologia em Democracia Digital (INCT.DD)
} 
Resumen: Este artículo tiene como objetivo mapear y discutir las iniciativas de participación digital impulsadas por las legislaturas brasileñas a nivel federal y estatal en respuesta a la pandemia provocada por el nuevo Covid-19 (Sars-CoV-2). Los resultados indican una abismal diferencia entre las iniciativas federales (65) y las estatales y del Distrito Federal (8). Mientras que las experiencias más robustas fueron impulsadas por la Cámara de Diputados (37) y el Senado Federal (28), a nivel subnacional solo la Cámara Legislativa del Distrito Federal (7) y la Asamblea Legislativa del Estado de Pernambuco (1) registraron casos. En los sitios web de las Asambleas Legislativas de los otros 25 estados no se registraron iniciativas que permitan a la sociedad participar en temas relacionados con la pandemia de Covid-19.

Palabras clave: Parlamento digital; Democracia digital; Participación en línea; Pandemia de Covid-19

\section{Introdução}

Com a emergência da pandemia da Covid-19, os governos precisaram tomar um conjunto de medidas não só em relação à saúde pública, mas também na economia, segurança pública, educação, entre outras dimensões que dizem respeito à vida em sociedade. Os desafios para a produção de respostas são grandes, entre outros motivos, porque a pandemia impôs uma nova forma de sociabilidade para todos os atores, inclusive para os agentes e autoridades públicas. No legislativo federal brasileiro, observamos um movimento rápido desde o primeiro momento para garantir a realização de sessões remotas voltadas especialmente às medidas legislativas cabíveis e à orientação e autorização dos gastos públicos no esforço de resposta à pandemia (MITOZO, 2020).

Por se tratar de um fenômeno novo, um conjunto de medidas legislativas precisaram ser tomadas para dar lastro às ações necessárias. Cabe, então, perguntarmos quais as possibilidades de participação as pessoas tiveram neste cenário em que as casas legislativas, via de regra, estiveram de portas físicas fechadas para o cidadão comum. Tomamos, então, como questão de pesquisa: Neste cenário da pandemia da Covid-19, quais foram os canais institucionais do legislativo federal e das unidades da federação para que a sociedade brasileira pudesse participar? Para responder essa questão, prospectamos iniciativas nos websites do Congresso Nacional, Senado Federal, Câmara dos Deputados e das Assembléias Legislativas de todos os estados, inclusive do Distrito Federal.

Muitos afirmam que, em tese, as condições de reação a esta pandemia seriam melhores do que outras que atingiram a humanidade em outros momentos por conta das tecnologias digitais de comunicação, que permitiram a manutenção, mesmo que de forma precária, do trabalho, comércio, educação, entre outras atividades individuais e coletivas. Em resumo, a vida humana em sociedade está em grande medida digitalizada - com importantes parcelas da população excluídas, registre-se - e isso nos daria melhores condições para responder às dificuldades provocadas diretamente ou indiretamente pela necessidade de distanciamento físico e suspensão de um conjunto de atividades presenciais entendidas como não essenciais no contexto de emergência. 
Este artigo está dividido em cinco partes. De partida, o leitor encontrará a discussão de alguns temas que apontam para a importância da participação no processo legislativo, particularmente no atual contexto. Na sequência, algumas notas metodológicas que serão seguidas pelos resultados. Por fim, pontuamos as implicações da dificuldade de incluir efetivamente a sociedade no processo legislativo, por mais que muito esteja sendo feito para dar transparência e visibilidade ao trabalho parlamentar nestes tempos de distanciamento físico.

\section{A Participação no Processo Legislativo e Pandemia do Covid-19}

$\mathrm{Na}$ clássica divisão dos poderes em executivo, legislativo e judiciário, cabe ao legislativo a formulação de leis e o monitoramento das ações do executivo. De acordo Gomes (2008), a partir de uma perspectiva habermasiana, os parlamentos são a solução encontrada pelos burgueses para institucionalizar a esfera pública dentro do estado (HABERMAS, 1984, 2003). A perspectiva habermasiana, conforme argumento de Gomes (2008), nos ajuda a entender que os parlamentos desempenham um importante trabalho político de processar as demandas da sociedade, chegadas sob formatos comunicacionais diversos - manifestações, abaixo-assinados, conteúdos midiáticos - e dar forma institucional - ofícios, discursos, seminários, projetos de lei - para as demandas que almejam se transformar em poder administrativo sob a forma de políticas públicas e leis.

Gomes (2008) desenvolve esse argumento para responder a crítica de Habermas à esfera pública contemporânea. Ao lembrar que o parlamento é um produto institucional das revoluções liberais contra as monarquias, Gomes (2008) entende que os atores que compõem a esfera pública devem se direcionar aos parlamentos como ambientes para a apresentação de demandas e politização de questões da vida em sociedade. Assim, firmamos o entendimento do trabalho legislativo como uma atividade que transforma demandas comunicativamente manifestadas em soluções a serem implementadas pela autoridade pública.

Essa linha de defesa de inspiração habermasiana nos ajuda a demonstrar a importância do desenho historicamente conformado dos legislativos nas democracias liberais contemporâneas, ressaltando a importância dos fluxos comunicacionais neste processo como centrais para um trabalho condizente com os interesses da cidadania, uma vez que os interesses não-legítimos têm mais dificuldade de se apresentar publicamente. Assim, a pesquisa democraticamente compromissada do fenômeno precisa se debruçar sobre a comunicação. Tanto a comunicação da sociedade endereçada aos corpos legislativos, quanto a importância da comunicação como ferramenta do legislativo para processar discursivamente as demandas da sociedade e dar forma institucional para que estas encontrem soluções. 
$\mathrm{O}$ crescente uso das tecnologias digitais tem sido apontado como fator potencialmente capaz de incrementar a comunicação entre agentes políticos e cidadãos, favorecendo, em tese, a representatividade, a participação e a transparência - princípios para um bom funcionamento do sistema democrático. Não obstante, autores como Coleman (2004) afirmam que, a despeito do fato de que os parlamentos nunca foram tão acessíveis, o desinteresse e alienação do público com relação ao processo legislativo se elevam sobremaneira.

Em trabalho mais recente (COLEMAN, 2017), o autor reconhece que pouco se avançou desde o início do século e do processo de incorporação do digital como possível resposta aos problemas da democracia representativa. Na visão do autor, não apenas as iniciativas de democracia digital de governos e legislaturas estão aquém das potencialidades ofertadas pela cultura digital, como há fatores que antecedem a mera possibilidade material e que dificultam o engajamento dos cidadãos. Analisando o cenário atual, Coleman cita como empecilhos para reduzir o abismo entre representantes e representados, a opacidade dos processos de tomada de decisão - o que leva o público a perceber a atividade política como alheia aos seus interesses e demandas - e a crise de confiança nos agentes e instituições do Estado. Aspectos que explicam a escassez de espaços de debate e deliberação genuínos no ambiente digital, ao menos no que diz respeito ao processo político institucional, uma vez que aplicação tecnológica na direção de maior abertura à participação cidadã depende de uma cultura política comprometida com os valores democráticos. Não se trata, portanto, de entender a tecnologia como um conjunto de "artefatos associais, neutros, com capacidades inatas para afetar a organização social"4 (COLEMAN, BLUMLER, 2009, p.10), mas de produto da sociedade, forjada no seio de um cultura e que, a despeito de possibilitar a ampliação dos canais e formas de comunicação entre representantes e representados, corre-se sempre o risco de que "esse potencial seja desperdiçado sem um desenho político imaginativo voltado para moldar e nutrir as oportunidades democráticas proporcionadas pela internet"5 (COLEMAN, BLUMLER, 2009, p.10).

Ao passo em que reconhece o potencial da tecnologia digital para o incremento do processo legislativo, sobretudo na sua dimensão comunicativa, Leston-Bandeira $(2009,2012)$ aponta para os desafios que subjazem a implementação de tais estratégias por parte dos parlamentos, dada sua natureza coletiva, a demanda por transparência e o caráter negociado das decisões tomadas no seu interior. As mudanças que se esperam dos parlamentos, que dependem de aspectos como letramento digital dos parlamentares, cultura política e disponibilidade de orçamento, não se operam na mesma velocidade das transformações tecnológicas, argumenta. Propondo um quadro analítico para a análise de parlamentos digitais, a autora enfatiza a necessidade de se observar fatores relativos às funções do legislativo, aos processos de

\footnotetext{
${ }^{4}$ Tradução nossa para "asocial, neutral artefacts with innate capacities to affect social organisation"

5 Tradução nossa para "such potential will be squandered without imaginative policy design to shape and nurture the democratic opportunities provided by the Internet"
} 
comunicação, disseminação e gestão da informação referentes às TICs, bem como para aspectos institucionais, particulares da realidade das casas (LESTON-BANDEIRA, 2007). Reconhecendo que as mudanças são incrementais, específicas dos diferentes contextos e muitas vezes em descompasso com as expectativas, a autora não deixa de defender que "em um mundo onde a internet se tornou parte integrante da rotina das pessoas, os sites dos parlamentos podem ser muito mais do que um mero repositório de informações; eles podem ser um mecanismo

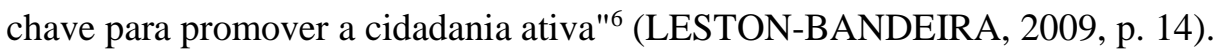

No contexto brasileiro, com a digitalização de todas as relações sociais, mas também das relações políticas e das instituições da República, estabelece-se consenso sobre a importância de que o legislativo aproveite os recursos da comunicação digital para se fazer mais transparente ou para admitir a participação da sociedade de modo mais sistemático (BARROS, 2016; BRAGA, MITOZO, TADRA, 2016; FARIA, 2012; MENDONÇA, AMARAL, 2014). Achados de Barros, Bernardes e Rodrigues (2014) apontam que o parlamento brasileiro é significativamente mais aberto à participação do que seus análogos no Mercosul. Na comparação com o parlamento britânico, Bernardes e Leston-Bandeira (2016) concluem que as casas brasileiras são superiores no que diz respeito às oportunidades de engajamento por parte dos cidadãos através dos recursos digitais.

Em ampla pesquisa realizada a partir da análise dos websites de todas as casas brasileiras, coletados em momentos diferentes, Braga, Mitozo e Tadra (2016) indicam que as ferramentas digitais têm papel importante no incremento da qualidade das funções desempenhadas por estas instituições - muito embora o desempenho digital das casas esteja associado a índices socioeconômico como IDH, PIB e inclusão digital. Resultados semelhantes foram encontrados por Griffith e Leston-Bandeira (2012) em pesquisa de nível global, relacionando o nível de desenvolvimento dos websites de parlamentos com índices de renda dos países.

A revisão sistemática das pesquisas sobre o portal e-Democracia, iniciativa da Câmara dos Deputados, realizada por Freitas et al. (2020) nos indica a consolidação de um campo interdisciplinar de pesquisa sobre os parlamentos digitais no Brasil. A autora e colegas revisaram a produção acadêmica entre 2009 e 2017 sobre a plataforma e encontraram 62 trabalhos, realizados por autores de 19 áreas do conhecimento diferentes, entre as quais destacam a Ciência Política (com 26,5\% da produção), Comunicação (12,5\%), o Campo de Políticas Públicas (11\%) e o Direito $(9,5 \%)$.

Certamente, a pandemia de Covid-19 impõe uma série de desafios para os sistemas políticos em todo o mundo, sobretudo os de natureza democrática. Ao refletir sobre as relações

\footnotetext{
${ }^{6}$ Tradução nossa para "In a world where the internet has become an integral part of peoples' routines, parliaments' websites can be much more than a mere information repository; they can be a key mechanism promoting active citizenship"
} 
entre crise sanitária e declínio democrático, Flinders (2020) conclui, a partir de uma análise documental, que há uma preocupação significativa com relação à escalada antidemocrática, à emergência de líderes populistas, ao crescente sentimento anti-política e à crise de confiança entre governos e governados. Circunstâncias que são anteriores ao novo Covid-19, mas cuja propagação pode servir de justificativa para ações políticas arbitrárias. Petrov (2020) afirma que a necessidade de medidas de saúde pública que limitam direitos e liberdades individuais acarreta no risco de que governos utilizem a emergência sanitária para consolidar seu poder político, livrando-se de suas limitações - como a atuação legislativa. O que, para o autor, é especialmente preocupante, "na era atual de engrandecimento do executivo, constitucionalismo populista abusivo e decadência democrática" (PETROV, 2020, p. 2).

Como aponta Flinders, acertadamente, o receio de que "a pandemia seja usada por populistas para diluir ainda mais ou remover as salvaguardas democráticas" (2020, p. 6) evidencia a importância da atuação parlamentar neste momento. No esteio do argumento de Barros e Sampaio (2016), entendemos que, particularmente neste momento de grande perda de vidas e piora da qualidade de vida por parte importante da população, escutar os cidadãos, suas histórias, sentimentos e emoções, é fundamental para que os legislativos consigam processar politicamente os anseios da sociedade.

Neste encargo, os recursos tecnológicos podem oferecer soluções para garantir a continuidade dos trabalhos do parlamento - a exemplo das sessões plenárias online. Sobre isso, Mitozo (2020) identificou que as assembleias de todas as unidades federativas, além das casas do Congresso Nacional, estabeleceram algum tipo de deliberação remota digital durante a pandemia, em diferentes níveis. Neste trabalho, não foram considerados os sistemas remotos de deliberação, por se tratarem de aplicações tecnológicas que dizem respeito à possibilidade de funcionamento dos parlamentos neste período, e não a iniciativas concebidas para viabilizar a participação do cidadão no processo de tomada de decisão.

\section{Metodologia}

A prospecção das iniciativas de participação voltadas à pandemia do Covid-19 aconteceu entre 29 de junho e 7 de julho de 2020, e foi realizada a partir de uma lista de todos os sites a serem visitados, isto é, os sites do Congresso Nacional, Senado Federal, Câmara dos Deputados e de todas as Assembleias Legislativas dos estados e do Distrito Federal. No total, visitamos 30 websites. Todas as casas legislativas estudadas têm websites com domínio .leg ou .gov, o que aumenta a encontrabilidade e segurança de que efetivamente visitamos os sites oficiais. Do total, 13 têm domínio .leg e 17 estão registrados com domínio .gov.

Então, procedemos a visita a todos os sites. Quando da identificação de uma iniciativa, fizemos o registro em uma tabela com os seguintes campos: i) nível, isto é, se federal, estadual 
ou do Distrito Federal; ii) identificação da Casa Legislativa; iii) nome da iniciativa; iv) link; e vi) tipo de iniciativa. Na observação, anotamos os seguintes tipos de iniciativa: audiências públicas; consulta; enquete; e petição.

A classificação dos tipos de iniciativa considerou categorias elencadas em pesquisas anteriores que se dedicaram a analisar iniciativas de democracia digital em sites de parlamentos (SETÄLÄ, GRÖNLUND, 2006; BERNARDES, LESTON-BANDEIRA, 2016), as quais trabalham com três grandes categorias: informações gerais sobre as instituições; informações sobre atividade legislativa, tais como projetos de lei; e recursos de interação, que permitem, em alguma medida, o engajamento do cidadão no processo legislativo. Neste trabalho, foram consideradas especificamente as iniciativas baseadas em recursos de interação. A partir do mapeamento das ações de participação foram identificadas quatro subcategorias, a saber: audiências públicas, enquetes, consultas e petições. A categorização de Almada e colegas (2019) para iniciativas de democracia digital promovidas pelo executivo federal também se faz presente nas escolhas classificatórias deste trabalho.

Importante ressaltar que nem toda ação que engaja o cidadão na relação com o legislativo implica em uma dimensão participativa. Ao examinar o papel dos recursos tecnológicos nas diferentes formas de engajamento público na relação com o legislativo, especificamente com o trabalho de comissões, Walker e colegas (2019) distinguem o processo em cinco fases, a saber: informação, compreensão, identificação, participação e intervenção. Nesta pesquisa, foram consideradas iniciativas alinhadas aos dois últimos passos. Fazendo um paralelo com a perspectiva de Gomes (2020), tratam-se, no caso da participação, de "ferramentas e projetos que permitem a chegada, o tratamento e a consideração de inputs ou contribuições provenientes dos cidadãos" e, no caso da intervenção, de "ferramentas e projetos que demandem e permitam colaboração dos cidadãos no processo de produção de leis [...] o que implica em compartilhamento de poder" (GOMES, 2020).

Os pesquisadores visitaram todos os links e menus apresentados no site com a preocupação de garantir que todas as páginas seriam inspecionadas, apesar de observarmos grandes diferenças no design e arquitetura da informação dos sites. A prospecção dos casos foi feita sempre por dois pesquisadores para evitar falso negativo. Os resultados dessa primeira incursão foram avaliados pelos três pesquisadores envolvidos no projeto para evitar falso positivo. Esse processo garantiu que casos previamente não catalogados fossem incluídos na tabela, bem como que outros fossem excluídos por não se adequarem aos critérios que estabelecemos. 


\section{As oportunidades de participação: audiências públicas, enquetes, consultas e petições}

De um total de 30 websites visitados, encontramos iniciativas em quatro deles. Ao todo, foram registradas 73 oportunidades para participação da sociedade, a maioria nas casas federais $(n=65)$. No Distrito Federal, a Câmara Legislativa realizou três consultas e quatro audiências públicas. Dos 26 estados, foi mapeada apenas uma oportunidade de participação, sob a forma de enquete, na Assembleia Legislativa do Estado de Pernambuco. O Senado Federal realizou 13 audiências públicas e 13 enquetes. A discrepância entre os níveis federal, distrital e estadual certamente é o resultado mais importante deste estudo.

Tabela 1 - Oportunidades de participação dos parlamentos brasileiros, em nível federal, estadual e do Distrito Federal, em temas relacionados ao Covid-19

\begin{tabular}{|c|c|c|c|c|c|c|}
\hline Nível & Casa & $\begin{array}{c}\text { Consulta } \\
\text { Pública }\end{array}$ & $\begin{array}{l}\text { Audiência } \\
\text { Pública }\end{array}$ & Enquete & Petição & Total \\
\hline Federal & $\begin{array}{l}\text { Senado } \\
\text { Federal }\end{array}$ & - & 13 & 11 & 4 & 28 \\
\hline Federal & $\begin{array}{c}\text { Câmara dos } \\
\text { Deputados }\end{array}$ & - & 37 & - & - & 37 \\
\hline Distrito Federal & $\begin{array}{l}\text { Câmara } \\
\text { Legislativa } \\
\text { (CLDF) }\end{array}$ & 3 & 4 & - & - & 7 \\
\hline Estadual & $\begin{array}{c}\text { Assembleia } \\
\text { Legislativa } \\
\text { do Estado de } \\
\text { Pernambuco }\end{array}$ & - & - & 1 & - & 1 \\
\hline Total & & 3 & 54 & 12 & 4 & 73 \\
\hline
\end{tabular}

Fonte: Os autores

\section{Estados e Distrito Federal}

$\mathrm{Na}$ Assembleia Legislativa do Estado de Pernambuco (Alepe), até a data da coleta dos dados, foi realizada uma enquete ${ }^{7}$ sobre o Projeto de Lei ${ }^{\circ} 1173 / 2020$ no qual é prevista a obrigatoriedade de que táxis e carros de transporte por aplicativo usem uma barreira plástica entre os assentos dianteiros e traseiros dos veículos para transporte de passageiros, devendo a mesma medida ser ampliada para cobradores de ônibus.. Diante desta proposta, o participante

\footnotetext{
${ }^{7}$ Disponível em: http://www.alepe.pe.gov.br/enquetes/ Acesso em: 14 set. 2020.
} 
pode escolher entre "preserva usuário e trabalhador", "é desnecessária e onerosa", ou "não tenho opinião formada". Para votar não foi necessário fazer cadastro ou muito menos logar no site. Bastou escolher umas das opções e clicar para que o voto fosse computado. O sistema registrou 367 votos. A primeira opção, preocupada em aumentar as barreiras físicas entre os ocupantes do carro, ficou com pouco mais de um quarto dos votos (103), enquanto a segunda opção que aponta a não-necessidade e o custo recebeu quase três quartos dos votos (259). 5 votos indicaram a inexistência de opinião formada por parte de seus autores.

A Câmara Legislativa do Distrito Federal (CLDF) adotou a plataforma e-Democracia ${ }^{8}$, fator aparentemente responsável pelo desempenho superior da casa frente às suas equivalentes estaduais no que diz respeito às iniciativas de participação online em resposta à pandemia embora a comparação com a Câmara Federal, com quantidade muito superior de casos, aponte para uma subutilização por parte da Câmara distrital. Até a data da coleta dos dados, foram realizadas quatro audiências públicas através da ferramenta Audiência Interativa: duas centradas no tema da educação durante a pandemia, uma sobre o papel do SUS no combate à Covid-19 e uma para discutir o combate à fome e à pobreza durante a crise sanitária. Assim como a plataforma utilizada pela Câmara dos Deputados, há um recurso de votação para as perguntas, de maneira que apenas as mais votadas são lidas e respondidas pela mesa. Há ainda um espaço para conversa entre os participantes (chat). A ferramenta também disponibiliza relatórios posteriores $(\log )$, com quantidade e registros textuais das perguntas realizadas e das mensagens trocadas no chat, além do número de visitantes e de participantes online de maneira simultânea. Das quatro audiências, três foram organizadas por um único deputado, Leandro Grass, o que indica um desequilíbrio no uso da plataforma entre os parlamentares.

No que diz respeito às iniciativas da categoria consulta, todas foram feitas por meio da ferramenta denominada Expressão, do portal e-Democracia da CLDF, que se apresenta como um fórum de discussão. Nota-se que os três casos de consultas registrados são derivações das audiências lideradas pelo deputado supracitado, com os mesmos temas, e que tiveram baixo nível de participação - apenas uma, "Realidades e desafios da Educação no DF em tempos de pandemia", teve respostas, com três registros.

\section{Câmara dos Deputados}

A Câmara dos Deputados capitaneou a maioria das iniciativas de participação online, com um total de 37 registros, todos de audiências públicas, até a data da coleta de dados. As audiências ocorreram através da ferramenta de Audiência Interativa do portal e-Democracia, pela qual o cidadão pode assistir e participar dos trabalhos, de maneira idêntica à utilizada pela CLDF e já descrita. Das 37 audiências realizadas, 33 foram iniciativas da Comissão Externa da

\footnotetext{
${ }^{8}$ Disponível em: https://edemocracia.cl.df.leg.br Acesso em: 14 set. 2020.
} 
Câmara dos Deputados destinada a acompanhar o Enfrentamento à Pandemia da Covid-19 no Brasil (CEXCORVI), formada por 23 deputados, com temas variados, na forma de reuniões técnicas com a presença de convidados, geralmente especialistas no ponto de pauta, representantes da sociedade civil e outros agentes políticos. Apenas três foram iniciativas individuais de parlamentares. Em geral, nota-se que muitas das discussões giram em torno de projetos de lei - caso da audiência sobre "Planos de Retomada das Atividades Comerciais e Serviços".

Foram registradas duas audiências focadas na situação de estados - Amazonas e Amapá. Nestas, os cidadãos puderam interagir, ainda que de maneira limitada às perguntas mais votadas, com parlamentares e agentes como governadores e secretários de estado. Pelo menos três iniciativas registraram a presença de ministros de estado - "Reunião Técnica com o Sr. General Eduardo Pazuello, Ministro da Saúde"; "Pesquisa, Inovação e Desenvolvimento", com Marco Cesar Pontes, da pasta de Ciência, Tecnologia e Inovações; e "A Situação dos Frigoríficos durante a pandemia do Covid-19", com Tereza Cristina, da Agricultura. Houve, ainda, uma audiência sobre "A Atuação do Poder Judiciário na Pandemia da Covid-19". São ações que apontam para a possibilidade de uso dos recursos tecnológicos como lugar de diálogo entre a sociedade e os três poderes, e não apenas com o parlamento.

Neste artigo, que tem um mapeamento como objetivo central, não nos aprofundaremos na análise das formas e níveis de participação possíveis de serem auferidos nas plataformas. Cabe, no entanto, sinalizar que há diferenças importantes no engajamento a depender do tema da audiência. Pautas relacionadas a questões econômicas parecem motivar a participação. A título de ilustração, a audiência sobre "Benefício de Prestação Continuada e Auxílio Emergencial" obteve 77 interações (22 perguntas e 55 mensagens), ao passo em que a discussão sobre "Mulher, Violência Doméstica e Covid-19" teve 16 respostas, sendo quatro perguntas e 12 mensagens.

Dentre as ações digitais da Câmara dos Deputados levantadas no período da pesquisa, não foram encontradas consultas ou enquetes. É incontestável que as audiências se configuram como espaços potencialmente mais propícios à participação na sua forma mais direta, dando lugar e voz ao cidadão no próprio processo de discussão dos projetos de lei. Não foram encontradas, porém, na plataforma de Audiências Interativas, evidências de que as intervenções dos participantes foram consideradas ou incorporadas às decisões sobre forma ou conteúdo das leis discutidas e aprovadas. Neste sentido, cabe assinalar que o portal e-Democracia disponibiliza uma ferramenta de edição de textos de projetos de lei, a Wikilegis, na qual não foram encontradas propostas relativas à pandemia. 


\section{Senado Federal}

As iniciativas de participação online do Senado Federal, num total de 28, foram disponibilizadas no site institucional e no e-Cidadania ${ }^{9}$ - sistema homólogo ao e-Democracia, porém hospedado no portal da casa. No e-Cidadania, há três formas de participação. Na seção Ideias Legislativas, na qual o cidadão pode sugerir projetos de lei, foram encontradas quatro propostas. Consideramos essa ferramenta uma petição, uma vez que a demanda pode ser avaliada se alcança ao menos 20 mil apoios. Em eventos interativos, o que inclui audiências públicas, foram registradas 13 iniciativas. No momento da prospecção, a ferramenta de consultas públicas estava em manutenção. No entanto, foram encontradas, na seção do Instituto Datasenado do site institucional, 12 iniciativas de enquetes de temas variados relacionados a medidas de combate à pandemia. Na relação foram consideradas como iniciativas de participação todas as classificadas no site como enquetes, bem como as pesquisas de opinião que incluíram questões relativas a projetos de lei. Do ponto de vista do resultado, é sabido que há diferenças importantes entre os dois tipos de ação - as pesquisas têm amostra probabilística, diferentemente das enquetes. No que diz respeito às formas de participação, porém, pesquisas e enquetes se assemelham, uma vez que procuram dar oportunidade ao cidadão de manifestar sua concordância ou discordância com relação a projetos de lei e outras medidas parlamentares - o que justifica que estejam agrupadas na mesma categoria.

Das 13 audiências públicas organizadas pelo Senado Federal, a maioria delas foi por meio da Comissão Mista Especial do Congresso Nacional de acompanhamento das medidas relacionadas ao Covid-19 (CN-Covid19). Apenas uma audiência foi iniciativa da Comissão de Transparência, Governança, Fiscalização e Controle e Defesa do Consumidor (CTFC), e ocorrida em data anterior à formação da CN-Covid19. De maneira semelhante às audiências conduzidas no e-Democracia, no caso do Senado Federal é possível ao cidadão interagir com os parlamentares e convidados, através de um sistema único para mensagens e perguntas. Algumas das perguntas são selecionadas para leitura e respondidas, sem que haja um critério claro na plataforma para essa escolha. Como ocorre na Câmara dos Deputados, nos eventos abertos à participação do Senado Federal o cidadão tem a possibilidade de deixar o lugar de mero espectador, mas com limitações e sem garantias de que sua intervenção será considerada no fazer legislativo.

\footnotetext{
${ }^{9}$ Disponível em: https://www12.senado.leg.br/ecidadania. Acesso em: 15 set. 2020.
} 


\section{Conclusões}

A resposta à pandemia do Covid-19 (Sars-CoV-2) que atingiu o Brasil em 2020 demandou uma série de medidas por parte do Legislativo, tanto para legislar em relação a medidas a serem tomadas por agentes públicos e privados, quanto para autorizar e fiscalizar a aplicação de recursos públicos para a promoção da saúde da população, mas também medidas econômicas, de segurança e educação públicas. O desafio tem sido maior porque também os legisladores precisam respeitar a recomendação de isolamento social. Os parlamentos estão com acesso físico restrito a poucas funções e a maior parte dos parlamentares está participando remotamente das sessões.

Neste cenário, aumenta a preocupação com as oportunidades institucionais que a sociedade tem para manifestar suas preferências em relação aos temas em discussão. Com as portas físicas fechadas para a sociedade, os canais digitais são salutares. Assim, procedemos um mapeamento e análise das iniciativas digitais de participação promovidas pelas casas legislativas brasileiras em nível federal e estadual. Os resultados indicam uma diferença abissal entre as iniciativas federais (65) e estaduais e do Distrito Federal (8). Isso a despeito da notória importância da atuação dos agentes públicos em nível estadual para a gestão da crise, e do alto grau de concernimento do público no assunto. Chama a atenção o fato de que mesmo casas que tradicionalmente apresentam desempenho elevado no uso das tecnologias digitais, tais como Minas Gerais, São Paulo, Santa Catarina e Rio de Janeiro (BRAGA, MITOZO, TRADA, 2016), não foram capazes de ofertar respostas de participação durante a crise, ao menos até o momento da prospecção feita por esta pesquisa.

Mesmo nas casas mais profícuas em iniciativas digitais, Câmara e Senado, limitações e desequilíbrios apresentam-se na observação mais atenta. Nenhuma ação de enquete, consulta ou petição foi registrada por parte dos deputados federais, por exemplo. A ferramenta de participação direta na produção de textos legislativos, Wikilegis, mostrou-se claramente subutilizada. Tampouco foram encontradas consultas públicas ou possibilidades de intervenção direta em projetos de lei nas ações digitais do Senado relativas à pandemia.

É significativo o desenvolvimento das audiências online, notadamente um formato que favorece a participação mais qualificada. O modelo desenvolvido pelo e-Democracia e também presente no e-Cidadania oferece recursos tecnológicos suficientes para promover a participação na sua mais elevada forma. O processo institucional que cerca as audiências, no entanto, carece ainda de ferramentas que possam evidenciar se e como as intervenções dos representados são incorporadas ao processo de tomada de decisão parlamentar, com critérios e procedimentos. Com isso, não defendemos que as iniciativas de participação sejam encarregadas da decisão, uma vez que quem tem a legitimidade para tanto são os representantes eleitos (argumento contra a democracia direta), mas que a pluralidade dos interesses e posições da sociedade possam 
encontrar oportunidades para se manifestar, preferencialmente mediante a apresentação de argumentos e não apenas em ferramentas com opções limitadas, para o fortalecimento das instituições representativas, uma vez que sua legitimidade e motivo fundam-se nos direitos do cidadão.

A julgar pelos números apresentados pela Câmara dos Deputados e pela Câmara Legislativa do Distrito Federal mediante o emprego do e-Democracia, nós entendemos que o uso de tal ferramenta por outras casas poderia viabilizar a existência de canais participativos. Vale registrar que a plataforma é um dos produtos do projeto Interlegis, mantido pelo Senado Federal, pode ser adotada por instituições e parlamentares do legislativo mediante convênio, que prevê não apenas a transferência dos códigos, mas também treinamento para parlamentares e funcionários dos legislativos ${ }^{10}$. Assim, como outros produtos do Interlegis tem desempenhando papel importante na promoção de transparência do processo legislativo, acreditamos que a plataforma e-Democracia pode ajudar na promoção da participação online no processo legislativo.

Como hipótese explicativa para os resultados que observamos, consideramos que o legislativo estadual não tinha, quando começaram as medidas de isolamento, ferramentas de participação bem desenvolvidas, bem como não dispunham de recursos para o desenvolvimento emergencial de tais interfaces. Neste contexto, em que os temas relacionados à pandemia estão no centro das preocupações da esfera pública, tema constante das conversas privadas, canais de participação por parte das Assembleias Estaduais poderiam ter aproximado a população do trabalho dos parlamentares. A partir de uma perspectiva normativa, defendemos que tais iniciativas poderiam garantir mais legitimidade e qualidade para as decisões tomadas. As portas do legislativo estadual estavam fechadas. As portas físicas pela necessidade de distanciamento social. As portas digitais para os interessados em participar.

\section{Referências}

ALMADA, Maria Paula; CARREIRO, Rodrigo; BARROS, Samuel; GOMES, Wilson da Silva. Democracia digital no Brasil. MATRIZes, v. 13, n. 3, p. 161-181, 2019.

BARROS, S. Os desafios das consultas públicas online: lições do Marco Civil da Internet. Liinc em Revista, v. 12, n. 1, 2016.

BARROS, Samuel A. R.; SAMPAIO, Rafael C. Do Citizens Trust Electronic Participatory Budgeting? Public Expression in Online Forums as an Evaluation Method in Belo Horizonte.

Policy and Internet, v. 8, n. 3, p. 292-312, 2016.

\footnotetext{
${ }^{10}$ Disponível em: https://www.interlegis.leg.br/produtos-servicos/e-democracia-1 Acesso em: 14 set. 2020.
} 
BRAGA, Sergio Soares; MITOZO, Isabele Batista; TADRA, Julia. As funções educativas dos e-Parlamentos: uma análise longitudinal do caso brasileiro. Cadernos de Pesquisa, v. 46, n. 162, p. 1192-1215, 2016.

BRAGA, Sérgio; SILVA, Sivaldo (org.). Parlamento Digital: Conceitos e práticas. Editora UnB, 2020. [no prelo].

BARROS, A. T.; BERNARDES, C. B., RODRIGUES, M. R. Digital Strategies of Political Interaction of Mercosur Parliaments. In: WORKSHOP OF PARLIAMENTARY SCHOLARS AND PARLIAMENTARIANS, 11.,Oxford, 2014.

BERNARDES, Cristiane Brum; LESTON BANDEIRA, Cristina. Information vs Engagement in parliamentary websites - a case study of Brazil and UK. Revista de Sociologia e Política, v. 24, n. 59, p. 91-107, set. 2016.

COLEMAN, Stephen. Connecting Parliament to the Public via the Internet. Information, Communication \& Society, v. 7, n. 1, p. 1-22, 2004.

COLEMAN, Stephen. Can the Internet Strengthen Democracy? Cambridge, Malden: Polity Press, 2017.

COLEMAN, Stephen, BLUMLER, Jay. The internet and democratic citizenship: theory, practice and policy. Cambridge University Press, 2009.

FARIA, Cristiano. O parlamento aberto na era da internet: pode o povo colaborar com o Legislativo na elaboração das leis?. Edições Câmara, 2012.

FLINDERS, Matthew. Democracy and the Politics of Coronavirus: Trust, Blame and Understanding. Parliamentary Affairs, , n. 13, Disponível em:

https://doi.org/10.1093/pa/gsaa013. jul. 2020. Acesso em: 10 ago. 2020.

FREITAS, Christiana Soares de; SAMPAIO, Rafael Cardoso; MACHADO, Henrique; SAMPAIO, Ricardo; BORGES, Tiago; ALISON, Murilo Brum; MARIOTO, Djiovanni Jonas França. Análise da Rede de Produção de Conhecimento sobre a Iniciativa E-democracia. Elegis, Brasília, n. 33, p. 182-203, set./dez. 2020.

GOMES, Wilson. Sobre o Campo do Parlamento Digital. In: BERNARDES, Cristiane; MITOZO, Isabele; BRAGA, Sérgio; SILVA, Sivaldo (org.). Parlamento Digital: Conceitos e práticas. Editora UnB, 2020. [no prelo].

GOMES, Wilson. A democracia no mundo digital. Histórias, problemas e temas. São Paulo: Edições Sesc São Paulo, 2018.

GOMES, Wilson. Participação política online: questões e hipóteses de trabalho. In: MAIA, R.C.M; GOMES, W. (ed.). Comunicação e democracia: problemas e perspectivas. São Paulo: Paulus, 2008.

GRIFFITH, Jeffrey; LESTON-BANDEIRA, Cristina. How Are Parliaments Using New Media to Engage with Citizens? The Journal of Legislative Studies, v. 8, n. 3-4, p. 496-513, 2012.

HABERMAS, Jürgen. Direito e democracia: entre facticidade e validade. Rio de Janeiro: Tempo Brasileiro, 2003. 
HABERMAS, Jürgen. Mudança estrutural da esfera pública: investigações quanto a uma categoria da sociedade burguesa. Rio de Janeiro: Tempo Brasileiro, 1984.

LESTON-BANDEIRA, C. The Impact of the Internet on Parliaments: a Legislative Studies Framework. Parliamentary Affairs, v. 60, n. 4, p. 655-674, 2007.

LESTON-BANDEIRA, C. Parliamentary functions portrayed on European parliaments' websites. Revista de Sociologia e Política, v. 17, n. 34, p. 13-27, 2009.

LESTON-BANDEIRA, C. Studying the relationship between Parliament and citizens. The Journal of Legislative Studies, v. 18, n. 3-4, p. 265-274, 2012.

LESTON-BANDEIRA, C. Why symbolic representation frames parliamentary public engagement. The British Journal of Politics and International Relations, v. 18, n. 2, p. 498-516, 2016.

MENDONÇA, Ricardo Fabrino; AMARAL, Ernesto Friedrich de Lima. Deliberações em consultas públicas? O caso da assembleia legislativa de Minas Gerais. Revista de Sociologia e Política, v. 22, n. 49, p. 177-203, mar. 2014.

MITOZO, Isabele. A utilização de sistemas deliberativos remotos pelas assembleias legislativas brasileiras durante a pandemia de Covid-19: características e prospectos. Revista do

Legislativo Paranaense, n. 4, p. 9-24, ago. 2020.

PETROV, Jan. The Covid-19 emergency in the age of executive aggrandizement: what role for legislative and judicial checks? The Theory and Practice of Legislation, jun. 2020. DOI: $10.1080 / 20508840.2020 .1788232$.

PINHO, José Antonio Gomes de. Investigando portais de governo eletrônico de estados no Brasil: muita tecnologia, pouca democracia. Revista de Administração Pública, v. 42, n. 3, p. 471-493, 2008.

SETÄLÄ, Maija; GRÖNLUND, Kimmo. Parliamentary websites: Theoretical and comparative perspectives. Information Polity, n. 11, p. 149-162, 2006.

WALKER, Aileen; JURCZAK, Naomi; BOCHEL, Catherine; LESTON-BANDEIRA, Cristina. How public engagement became a core part of the House of Commons Select Committes.

Parliamentary Affairs, vol. 72, n. 4, p. 965-986, out. 2019. 